\title{
A MATHEMATICAL METHOD FOR PREVENTING INCONSISTENCY IN DECISION MAKER'S COMPARISONS
}

\author{
Soheila Amirabadi \\ Faculty of Industrial Engineering \\ Alzahra Univars ity \\ Tehran, Iran \\ Email: amirabadis oheila@gmail.com
}

\begin{abstract}
The AHP method requires that decision maker remain consistent in making pairwise comparisons among numerous decision criteria and it becomes more difficult when the number of criteria and alternatives increase. Although Saaty proposed a method to assess the consistency of pairwise comparisons, no automatic method exist for improving the consistency. This research results in a method for leading the fuzzy mental approach of comparison to the mental mathematical approach, in order to achieve consistency in final comparison matrix in regard to decision maker's preferences.
\end{abstract}

Keywords: Pairwise comparison, priority, inconsistency, Analytical Hierarchy Process.

\section{Introduction}

Since Saaty (1977) introduced the Analytical Hierarchy Process (AHP), many applications in real-world decision-making have been reported (Zahedi,1986; Shim, 1989; Vargas, 1990; Saaty, 2000; Forman and Gass, 2001; Golden and Wasil, 2003; Vaidya and Kumar, 2006). In parallel, AHP has been criticized in the literature, from several perspectives (Watson and Freeling, 1982,1983 ; Belton and Gear, 1983, 1985; Dyer, 1990; Barzilai and Glany, 1994). Among the problems verified by researchers, inconsistency is almost the cause of other problems.

In fact, the decision maker is involved in the creative and data input stages rather than in the computational stages. The one exception to this is if the decision maker's pairwise comparisons fail the consistency test. If pairwise comparisons fail the consistency check, the conclusion is that the decision maker has been illogical or has made a mistake in the pairwise comparison assessment. The recommended course of action is for the decision maker and to get the decision maker to revise his assessment so that they are no longer incons istent.

Karapetrovic and Rosenbloom (1999) believe this attempt revision of the pairwise comparisons is generally not very successful. Often the decision maker has not made a mistake. Usually decision makers are quite conscientious in evaluating the pairw ise comparisons. The pairwise comparisons that decision makers make are rarely random even if they fail the consistency check. In fact, the ability of humans for accurately expressing their knowledge decreases with increasing problem complexity. Thus, as the number of criteria in AHP increases, decision makers are likely to make inconsistent judgments during pairwise comparis ons (Lin, Wang \& Yu, 2008). 
Therefore, how to adjust the inconsistency has been addressed by many studies (Saaty T.L., Vargas LG, 1984; Xu Z, Cuiping W, 1999; Jensen RE,1984; Saaty T.L., 2003). These methods mainly based on the eigenvector approach. According to Li and Ma (2007), although these methods can largely improve inconsistencies, the adjusted matrix, however, may be far beyond the real preferences acceptable by the decision maker and the decision maker should make the final changes, rather than having changes automatically made.

Thus, we concluded that if we find an approach for helping the decision maker make an accurate consistent decision at first step the decision maker will not face any problem in using Saaty's AHP method. In our opinion, If we find a way for leading the comparison first step, which is somehow a mental fuzzy step, to a mental mathematical process, the decision maker's duty will decrease but still he has the main effect on the final conclusion .Besides, this kind of approach is less time consuming and completely explains the decision maker's preferences in compare to revisioning the comparisons

\section{Explanation of proposed comparison approach}

According to our proposed approach, instead of comparing each alternative with other alternatives, the decision maker should do the first line comparison of the matrix, then other relative comparisons will be derived from that first line. In fact the decision maker's priorities is unique and the fuzzyness occures in comparisons is the result of mind confusion of him after entering many values and trying to remmember previouse priorities. So if the decision maker enter just one set of values he can focuse on his comparisons and find that unique priorities in his mind.

Suppose that for a $4 \times 4$ matrix that person $\mathrm{j}$ wants to judge, he assigned numbers $\{a, b, c, d\}$, for relative priority of alternatives $\left\{x_{1}, x_{2}, x_{3}, x_{4}\right\}$. Other comparisons will be calculated in refrence to these alternatives and no other data entering is needed.

From the first line that entered by the decision maker we have:

$\left\{x_{1}, x_{2}\right\}: x_{1}$ dominates $x_{2}$, a times.

$\left\{x_{1}, x_{3}\right\}: x_{1}$ dominates $x_{3}, \mathrm{~b}$ times.

$\left\{x_{1}, x_{4}\right\}: x_{1}$ dominates $x_{4}$, c times.

It is as same as:

$x_{1}=a x_{2}=b x_{3}=c x_{4}$

From above equation we conclude:

$\left\{x_{2}, x_{3}\right\}: x_{2}$ dominates $x_{3}, \frac{b}{a}$ times.

$\left\{x_{2}, x_{4}\right\}: x_{2}$ dominates $x_{4}, \frac{c}{a}$ times.

$\left\{x_{3}, x_{4}\right\}: x_{3}$ dominates $x_{4}, \frac{c}{b}$ times.

And remained values under the main diameter is inversed of above it. The corresponding matrix is 


$$
\mathrm{A}=\begin{gathered}
x_{1} \\
x_{2} \\
x_{3} \\
x_{4}
\end{gathered}\left(\begin{array}{cccc}
x_{1} & x_{2} & x_{3} & x_{4} \\
1 & a & b & c \\
1 / a & 1 & b / a & c / a \\
1 / b & a / b & 1 & c / b \\
1 / c & a / c & b / c & 1
\end{array}\right)
$$

To show the workability of this method we have present the $7 \times 7$ example of Saaty (2008) which compares the popularity of consumption of different drinks in the USA. Our reason for choosing this example is availability of actual consumption values beside AHP model priorities and accordingly, feasibility of comparing three series priorities.

According to Saaty (2008) the comparison matrix with Consistency Ratio (CR) of 0.022 is:

\begin{tabular}{|c|c|c|c|c|c|c|c|}
\hline Saaty's pairwise comparison & Coffee & Wine & Tea & Beer & Soda & Milk & Water \\
\hline Coffee & 1 & 9 & 5 & 2 & 1 & 1 & $1 / 2$ \\
\hline Wine & $1 / 9$ & 1 & $1 / 3$ & $1 / 9$ & $1 / 9$ & $1 / 9$ & $1 / 9$ \\
\hline Tea & $1 / 5$ & 2 & 1 & $1 / 3$ & $1 / 4$ & $1 / 3$ & $1 / 9$ \\
\hline Beer & $1 / 2$ & 9 & 3 & 1 & $1 / 2$ & 1 & $1 / 3$ \\
\hline Soda & 1 & 9 & 4 & 2 & 1 & 2 & $1 / 2$ \\
\hline Milk & 1 & 9 & 3 & 1 & $1 / 2$ & 1 & $1 / 3$ \\
\hline Water & 2 & 9 & 9 & 3 & 2 & 3 & 1 \\
\hline
\end{tabular}

In accordance with the proposed approach, by using the first line of above matrix the resulted matrix will be:

\begin{tabular}{|c|c|c|c|c|c|c|c|c|}
\hline $\begin{array}{l}\text { Proposed } \\
\text { approach }\end{array}$ & comparison & Coffee & Wine & Tea & Beer & Soda & Milk & Water \\
\hline Coffee & & 1 & 9 & 5 & 2 & 1 & 1 & $1 / 2$ \\
\hline Wine & & $1 / 9$ & 1 & $5 / 9$ & $2 / 9$ & $1 / 9$ & $1 / 9$ & $1 / 18$ \\
\hline Tea & & $1 / 5$ & $9 / 5$ & 1 & $2 / 5$ & $1 / 5$ & $1 / 5$ & $1 / 10$ \\
\hline Beer & & $1 / 2$ & $9 / 2$ & $5 / 2$ & 1 & $1 / 2$ & $1 / 2$ & $1 / 4$ \\
\hline Soda & & 1 & 9 & 5 & 2 & 1 & 1 & $1 / 2$ \\
\hline Milk & & 1 & 9 & 5 & 2 & 1 & 1 & $1 / 2$ \\
\hline Water & & 2 & 18 & 10 & 4 & 2 & 2 & 1 \\
\hline
\end{tabular}

Now we can compare the final priorities of these two different comparison approaches and compare them with actual priorities was obtained from the US Statistical Abstracts.

As you see in the Table 1, the weights are close and the priorities which are more important than the weights are almost the same. The reason of facing equal values for coffee, soda and milk is the limitation of Saaty for entering descrete 1/9-1 and 1-9 values which can be prevented by using in between values to obtain the best priorities. Therefore, proposed approach judgements of a person who knows can lead to accurate priorities even with just $n-1$ comparisons instead of $n(n-1) / 2$ comparisons. 
Table 1. weights of Saaty (2008) example using Pairwise and proposed method beside Actual weights.

\begin{tabular}{|l|l|l|l|}
\hline & Pairwise method weights & Proposed method weights & Actual statistical weights \\
\hline Coffee & 0.177 & 0.171 & 0.180 \\
\hline Wine & 0.019 & 0.019 & 0.010 \\
\hline Tea & 0.042 & 0.054 & 0.040 \\
\hline Beer & 0.116 & 0.07 & 0.120 \\
\hline Soda & 0.190 & 0.171 & 0.180 \\
\hline Milk & 0.129 & 0.171 & 0.140 \\
\hline Water & 0.327 & 0.343 & 0.330 \\
\hline
\end{tabular}

Table 2. Weights of Lee, Pham and Zhangs' (1998) example with different methods. The original matrix's consistency ratio $(\mathrm{CR})$ is 0.031 .

\begin{tabular}{|l|l|l|l|l|}
\hline alternatives & $\begin{array}{l}\text { Pairwise } \\
\text { method }\end{array}$ & rank & $\begin{array}{l}\text { proposed } \\
\text { method }\end{array}$ & rank \\
\hline Toyota Camry & 0.274 & 2 & 0.242 & 2 \\
\hline Nissan Maxima & 0.515 & 1 & 0.605 & 1 \\
\hline Honda Accord & 0.146 & 3 & 0.097 & 3 \\
\hline Mazda 626 & 0.065 & 4 & 0.057 & 4 \\
\hline
\end{tabular}

According to Karapetrovic and Rosenbloom (1999), revision of the pairwise comparisons is generally not very successful. Often the decision maker has not made a mistake. Usually decision makers are quite conscientious in evaluating the pairwise comparisons. The pairwise comparisons that decision makers make are rarely random even if they fail the consistency check. In fact, the ability of humans for accurately expressing their knowledge decreases with increasing problem complexity. Thus, as the number of criteria in AHP increases, decision makers are likely to make inconsistent judgments during pairwise comparisons (Wang et al., 2008). But with our proposed method the decision maker will concentrate on his first step for judging just one set of alternatives and he will build the comparison matrix on the basis of those comparisons. The advantageousness of this method is being less timecosuming that results in less cost besides solving the inconsistency problem.

To prove the claim by way of example we have solved some other examples of other researchers' in different sizes with proposed method and we have compared the resulted priorities with Saaty's method priorities. The examples were taken from Saaty's (2008) with original consistemcy ratio of 0.074, Bana e Costa and Vansnicks' (2008) with consistency ratio of 0.050 and Tam and Tummalas' (2001) with consistency ratio of 0.03 . These results show that this method works in almost every consistent situation but In spite of situations this method works in, there are some situations in which this approach doesn's result in the priorities as same as pairwise comparison priorities. It means if you do some examples randomly you can find some counter examples. But use of this method by someone knwoledgeable for comparing alternatives can result in logical acceptabale prioritization.

In Saaty's (2006) example with consistency ratio of 0.112 and Conklin and Lipovetskys' (2002) example with consistency ratio of 0.170 primary consistency ratio is more than 0.1 and it means that the decision maker has been inconsistent in his judgements. But if we see the priorities, we can conclude just in Conklin and Lipovetskys' (2002) in which its CR is higher, the priorities with our proposed method have changed. 


\section{Conclusion}

This approach which helps the decision maker do the comparisons consistently. It means that our approach based on mathematical solutions in parallel with mental part that is based on decision maker's priorities. Because of that the dicision maker still has the main effect on final result although he uses this mathematical approach. The advantageousness of this method is being less time-cosuming that results in less cost besides solving the inconsistency problem. The only point about this approach is that it is applicable for informed decision makers.

\section{REFERENCES}

Bana e Costa, C.a. \& Vansnick, J.C. (2008). A critical analysis of the eigenvalue method used to derive priorities in AHP. European Journal of Operational Research, 187, 1422-1428.

Barzilai, J., Golany, B. (1994). AHP rank reversal, normalization and aggregation rules. INFOR, (32), 5764.

Belton, V., Gear, A.E. (1983). On a shortcoming of Saaty's method of analytic hierarchies. Omega, 11 (3), 228-230.

Belton, V., Gear, A.E. (1985). The legitimacy of rank reversal - a comment. Omega, 13 (3), 143-144.

Cuiping, W. \& Xu, Z. (1999). A consistency improving method in the analytic hierarchy process. European Journal of Operational Research, 116, 443-449.

Dyer, J.S. (1990). Remarks on the analytic hierarchy process. Management Science, 36 (3), 249-258.

Forman, E.H., Gass, S.L. (2001). The analytic Hierarchy Process: An exposition. Operations Research, 49 (4), 469-486.

Golden, B. \& Wasil, E.A. (2003). Celebrating 25 years of AHP-based decision making. Computers and Operations Research 30 (10), 1419-1497.

Jensen, R.E. (1984). An alternative scaling method for priorities in hierarchical structures. Journal of Mathematical Psychology, 28 (6), 317-332.

Kumar, S. \& Vaidya, O.S. (2006). Analytical hierarchy process: An overview of applications. European Journal of Operational Research, 169 (1), 1-29.

Lipovetsky, S. \& Conklin, W.M. (2002). Robust estimation of priorities in the AHP. European Journal of Operational Research, 137, 110-122.

Ma, L.C. \& Li, H.L. (2007). Detecting and adjusting ordinal and cardinal inconsistencies in through a graphical and optimal approach in AHP models. Computer and Operations Research, 34, 780-798.

Pham, H., Lee, M. \& Zhang, X. (1999). A methodology for priority with application to software development process. European Journal of Operational Research, 188, 375-389.

Rosenbloom, E.S \& Karapetrovic, S. (1999). A quality control approach to consistency paradoxes in AHP. European Journal of Operational Research, 119, 704-718. 
Saaty, T.L. (1977). A scaling method for priorities in hierarchical structures. Journal of Mathematical Psychology, 15 (3), 234-281.

Saaty, T.L. (2000). Fundamentals of the Analytical Hierarchy Process. RWS publications, Pittsburgh, PA15213-28072000.

Saaty, T.L. (2003). Decision-making with the AHP: why is the principal eigenvector necessary. European Journal of Operational Research, 145, 85-91.

Saaty, T.L. (2006). Rank from comparisons and from ratings in the analytic hierarchy/network process. European Journal of Operational Research, 168, 557-570.

Saaty, T.L, (2008). Decision making with the analytic hierarchy process. Int. J. Services Sciences, 1 (1), 83-98.

Saaty, T.L. \& Vargas LG. (1984). Comparison of eigenvalue, logarithmic least squares and least squares method in estimating ratios. Mathematical Modeling. 5 (5), 309-324.

Shim, J.P. (1989). Bibliography research on the analytic hierarchy process (AHP). Socio-Economic Planning Sciences, 23 (3), 161-167.

Tummala, V.M.R., Tam, M.C.Y. (2001). An application of the AHP in vendor selection of a telecommunications system. Omega, 29 (2), 171-182.

Vargas, L.G. (1990). An overview of the analytic hierarchy process and its applications. European Journal of Operational Research, 48 (1), 2-8.

Wang, W.C., Lin, C.C. \& Yu, W.D. (2008). Improving AHP for construction with an adaptive AHP approach $\left(\mathrm{A}^{3}\right)$. Automation in Construction, 17, 180-187.

Watson, S.R., Freeling, A.N.S. (1982). Assessing attribute weights. Omega, 10 (6), 582-583.

Watson, S.R., Freeling, A.N.S. (1983). Comment on: Assessing attribute weights by ratios. Omega, 11 (1), 13.

Zahedi, F. (1986). The analytical hierarchy process- A survey of the method and its applications. Interfaces, 16 (4), 96-108. 